\title{
Prevalence of Hypertension in the Urban Population of Catanduva, in the State of São Paulo, Brazil
}

\author{
Olavo de Carvalho Freitas, Fabiano Resende de Carvalho, Juliana Marques Neves, Paula Karine Veludo, \\ Ricardo Silva Parreira, Rodrigo Marafiotti Gonçalves, Simone Arenales de Lima, \\ Reinaldo Bulgarelli Bestetti \\ Catanduva, SP - Brazil
}

Objective - To study the prevalence of systemic hypertension and its control in the population of Catanduva, in the state of São Paulo, Brazil.

Methods - We carried out a randomized cross-sectional population-based study of the urban population of $\mathrm{Ca}$ tanduva with individuals above 18 years of age (688 individuals accounting for $0.9 \%$ of the referred population). We interviewed study participants to analyze the major qualitative and quantitative variables that could influence the hypertensive scenario and the risk for systemic hypertension. Blood pressure was measured through the indirect method according to the III Consenso Brasileiro de Hipertensão (III Brazilian Consensus on Hypertension), which established blood pressure levels $\geq 140 / 90 \mathrm{~mm} \mathrm{Hg}$ as hypertensive.

Results - The prevalence of systemic hypertension was higher in individuals with: (1) history of hypertension $(p<0.0001)$; (2) diabetes mellitus ( $p=0.05)$; (3) body mass index (B. M.I) $\geq 25 \mathrm{~kg} / \mathrm{m}^{2}(p<0.001)$; (4) loweducational level $(p<0.0001)$; (5) familial income ranging from 1 to 5 minimum wages ( $<<0.05$ ); (6) unmarried status (divorced/separated and widow(er)s) $(p<0.0001)$. Of the interviewed individuals, $27.6 \%(p=0.05)$ had blood pressure levels under control.

Conclusion - Our study showed that the prevalence of systemic hypertension was $31.5 \%$, and that $27.6 \%$ of the individuals interviewed had blood pressure levels under control at the time of the interview.

Keywords- hypertension, antihypertensive treatment, epidemiological study of hypertension

Faculdade de Medicina de Catanduva - FAMECA

Mailing address: Olavo de Carvalho Freitas - FAMECA - Depto. de Ciências Fisiológicas - Disciplina de Fisiologia - Av. São Vicente de Paula, 1455 - 15800-000 - Catanduva, SP, Brazil - E-mail: fisiofrc@uol.com.br

(English version by Stela Maris C. e Gandour)
Several studies on prevalence of systemic hypertension exist in the international medical literature ${ }^{1-7}$. In Brazil, these values have ranged from $16.1 \%$ to $35.1 \%^{8-16}$, depending on the ethnic and social groups studied and on the parameters proposed as the defined limits of hypertension.

In Brazil, some studies assess the association between systemic hypertension and demographic characteristics, such as age bracket, ethnic group, socioeconomic level, smoking, alcohol consumption, salt ingestion, stress, diabetes, and obesity ${ }^{8-16}$. However, little attention has focused on the control of antihypertensive treatment, which accounts for therapeutical failure in more than $60 \%$ of the cases ${ }^{13,17-19}$

In the Northwestern region of the state of São Paulo there are municipalities with a high socioeconomic level, such as Catanduva, and their economy are based on the citric and sugar cane agroindustry and also on the tertiary sector industry. Therefore, some of these municipalities have a quality of life similar to that observed in developed countries. Our study aims to assess the prevalence of systemic hypertension associated with some of the above-cited factors in Catanduva. The total population estimated for the city in 1998 was 103,889 inhabitants, 77,598 of whom were above 18 years of age. The prevalence of the male sex was observed until the age of 50 years, according to the IBGE (Brazilian Institute of Geography and Statistics).

\section{Methods}

An analytical cross-sectional population-based study with randomized sampling ${ }^{20}$ was carried out. The population analyzed comprised 688 essentially urban individuals $(0.9 \%$ of the entire population) with ages above 18 years ( $74.7 \%$ of the entire population), who lived in the municipality of Catanduva, and whose origin was not important, according to data of the 1996 census and the IBGE's forecast for 1998. Of the 688 individuals interviewed, 286 were males and 402 
were females. The relative disproportion between males and females was mainly due to the fact that more men than women are in the workforce and therefore men were not readily available to interview. To minimize this effect, the interviews were performed early in the morning to include men before they had to go to work.

To avoid sampling errors, the city was divided into 40 sectors, in which the number of dwellings and the social groups contained did not matter. These sectors were selected, and the study began with the first selected sector, and so on. In each sector, 3 dwellings per block were randomly chosen. No dwelling was excluded, not even those without sewage or electricity. If the inhabitants of the selected dwelling could not participate or if the dwelling was empty, the nearest dwelling was then chosen to meet the criterion established.

The research team comprised 2 teachers (cardiologists), 6 medical students (interviewers), and 1 software specialist. The medical students were properly trained and oriented to administer the questionnaires and to measure the anthropometric parameters. The interviewers wore badges of the Faculdade de Medicina de Catanduva to facilitate contact with the population and data collection ${ }^{17}$.

According to the III Brazilian Consensus on Hypertension of $1998^{18}$, systemic hypertension is defined as systolic pressure $\geq 140 \mathrm{mmHg}$ and diastolic pressure $\geq 90 \mathrm{mmHg}$ (for individuals older than 18 years) ${ }^{19}$. These criteria were adopted by the interviewers.

The interview had a mean duration of 30 minutes, being performed from 6 to 10 a.m. ${ }^{19-23}$ daily from February 2 to April 4, 1998. The team was distributed in 3 pairs of interviewers, each pair comprising individuals of both sexes. The pairs of interviewers were changed and the criteria of the interview were reassessed weekly.

After explaining to the interviewee the objectives and procedures of the study, 1 of the interviewers collected the personal data and, then, the other interviewer measured the anthropometric data and the blood pressure level. The interview comprised assessment of qualitative and quantitative variables, such as age, sex, race, profession, daily work load, marital status, educational level, familial income, use of medication that could positively influence hypertension (tricyclic antidepressants, monoamine oxidase inhibitors, oral contraceptives), as well as antihypertensive drugs and their use, regular or not. The following parameters were also assessed: dietary habits (amount of meat, number of eggs, number of milk liters ingested per day or weekly), salt ingestion (quantification was based on the presence of the salt container on the table, as no salt quantification in grams was performed because of the difficulty that this would imply), smoking (number of cigarettes smoked daily), ethanol ingestion (if higher than $30 \mathrm{~mL}$ per day), number of annual medical visits for blood pressure assessment, weekly programmed physical activity, antecedents of hypertension on firstdegree relatives, previous knowledge of hypertension, dwelling conditions, and satisfaction at home and at work ${ }^{21-26}$. The criterion for considering a physical activity was the practice of physical exercises 3 or more times a week for a minimum period of 45 minutes each time ${ }^{18,21,22}$. All interviewees were asked about the above-cited items, in the that sequence. They received no questionnaire to fill out.

After one medical student administered the questionnaire, the other medical student measured the blood pressure level through the indirect method using an aneroid sphygmomanometer, which is less accurate than the mercury one, but more appropriate for field research because it is easier to handle and is less often rejected by the interviewees ${ }^{21,23}$. Before blood pressure measurement, the interviewee rested for 5 minutes in a calm environment with a pleasant temperature, remaining seated on a chair with 1 of the arms resting on a table, at heart level. The brachial artery of the right arm was located by palpation. The cuff was firmly placed 2 to $3 \mathrm{~cm}$ above the cubital fossa over the brachial artery, centralizing the rubber bag above it. Korotkoff phases determined systolic and diastolic pressures as follows: phase I determined systolic pressure, and phase $\mathrm{V}$ determined diastolic pressure. After 3 minutes, a new measurement of blood pressure was performed. The mean of both measurements was obtained ${ }^{18}$. At the end, height was measured with a tape measure, and the interviewee was weighed for calculating the body mass index.

For measuring blood pressure, the interviewee should not have performed the following activities in the 30 minutes prior to the interview: practiced physical exercises, drunk alcoholic beverages or coffee, ingested food, and smoked ${ }^{17-21}$. If the interviewer noticed any emotional change in the interviewee, the examination was postponed. After the assessment, the medical student provided a brochure with information on systemic hypertension prevention and its predisposing factors to the interviewee. In addition, every hypertensive interviewee received recommendations for more effective compliance with the antihypertensive treatment ${ }^{27-30}$. The individual who ignored his hypertensive condition was informed of his condition and advised to get a more comprehensive assessment at the medical service of the medical school of Catanduva ${ }^{17}$. The address of the hypertensive individual was recorded for future reassessments.

Aneroid sphygmomanometers of a single brand were used, and they were properly calibrated every 15 days. Stethoscopes, scales, and measuring tapes were also of a single brand to avoid technical deviations in values because of the material used ${ }^{23}$.

Software in the Delphi language for Windows was developed for analyzing, formulating, and computing the results.

Fisher exact test was used for comparing the proportion of noncontinuous variables between 2 groups. The significance level adopted was lower than or equal to 0.05 .

\section{Results}

The prevalence of hypertension in the municipality of Catanduva was $31.5 \%(n=217)$, corresponding to $0.9 \%$ of 
the sample of 77,598 inhabitants. The prevalence of isolated diastolic hypertension was $14.8 \%(\mathrm{n}=102)$, the prevalence of isolated systolic hypertension was $6.5 \%(n=45)$, and that of systolic/diastolic hypertension was $10.2 \%(\mathrm{n}=70)$.

The prevalence of systemic hypertension was $33.9 \%$ for the male sex $(n=286)$ and $29.9 \%$ for the female sex $(n=402)$, in population above 18 years of age in the municipality $(77,598)$. Figure 1 shows the systolic and diastolic blood pressure levels in the respective age brackets for both sexes. In regard to the hypertensive population, $44.7 \%(n=97)$ were of the male sex and $55.3 \%(n=120)$ of the female sex.

The prevalence of systemic hypertension for individuals working up to 6 hours per day was $20.7 \%$ and for those working 8,10 , and 12 hours it was, respectively, $21 \%$, $29.3 \%$, and $28.3 \%$. The workload was systematically observed, and in regard to those women who answered they were housewives and did not have a helper, they were placed in the $12 \mathrm{~h}$ group.

In regard to the interviewees $(\mathrm{n}=688), 577(84.1 \%)$ were white, $107(15.5 \%)$ were black (individuals resulting from miscegenation were considered as black people), and 4 were individuals of Far Eastern heritage, 3 of whom were hypertensive. These latter values were not included in the percentages because they constituted a very small group. The population of the municipality of Catanduva has a predominance of white individuals as compared with most Brazilian cities, because of the high concentration of Italian immigrants and their descendants there. This fact resulted in an unexpected percentage of $31.8 \%$ of white hypertensive individuals and $29 \%$ of black hypertensive individuals,

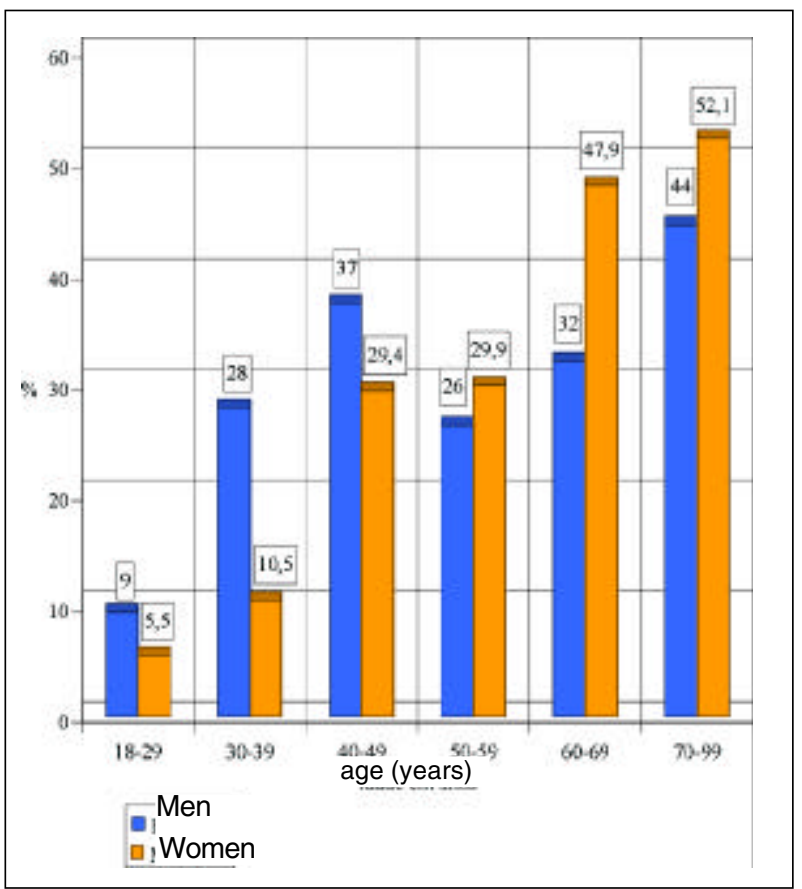

Fig. 1 - Prevalence of systemic hypertension in the female and male sex in different age brackets. considering that 577 of the interviewees were white and 107 were black, a fact already reported in a previous study ${ }^{10}$.

In regard to the educational level, which is a variable rarely studied in the medical literature, we observed that $49.5 \%$ of the illiterate individuals $(\mathrm{n}=107)$ had systemic hypertension and only $12.7 \%(n=71)$ of the individuals who had completed the university educational level had hypertension ( $\mathrm{p}<0.0001$ ). Figure 2 shows the percentage relation between educational level and systemic hypertension.

Another result of our study, which had not been reported in the literature, was the higher prevalence of systemic hypertension in the unmarried group (divorced/separated and widow(er)s) as compared with that of the married group $(\mathrm{p}<0.0001)$, which deserves a further assessment (Table I and fig. 3). The bachelors were not included in the unmarried group because of their predominantly low age bracket.

The criterion for analyzing the control of the treatment followed the algorithm in chart I. The medication being used was analyzed in detail, and an inquiry about changes in lifestyle was performed. If the interviewee did not have a strict change in lifestyle, he was excluded from this group. In regard to the elderly, an exception was considered for those who were not in condition to exercise due to any type of physical incapacity. However, even if not participating in physical exercise, if the individual met the remaining criteria for changes in lifestyle, he would be included in the group. The results of this cross-sectional analysis are shown in chart I.

In regard to familial income, our results seemed to be related to the educational level; this correlation, however, was not exactly contiguous (fig. 4).

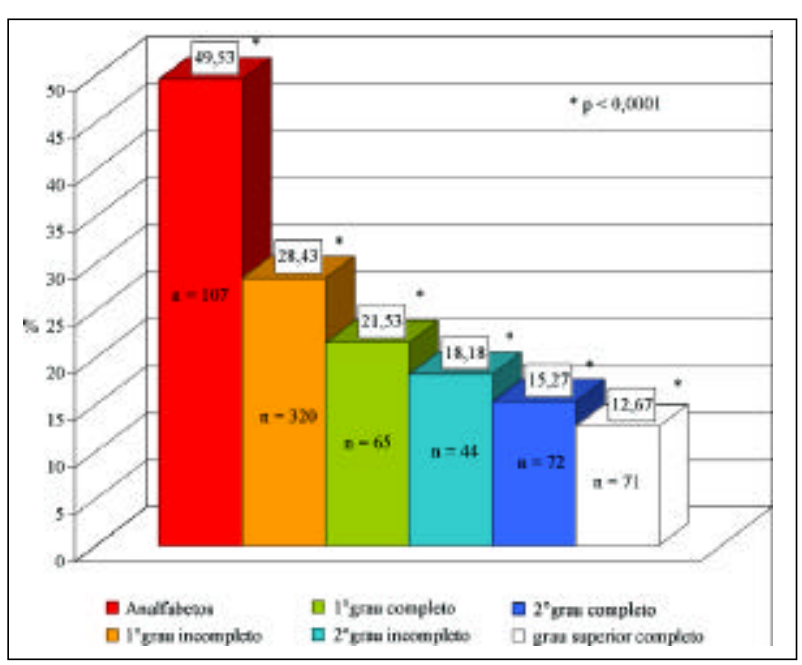

Fig. 2 - Comparison of blood pressure levels of hypertensive individuals with their respective educational levels in the municipality of Catanduva $(\mathrm{p}<0.0001)$.

\begin{tabular}{|llll|}
\hline $\begin{array}{c}\text { Table I - Prevalence of systemic hypertension in the married and } \\
\text { unmarried groups in the municipality of Catanduva }\end{array}$ \\
\hline Married & $25.77 \%$ & $\mathrm{~N}=454$ & $\mathrm{P}<0.0001$ \\
Divorced/separated & $29.82 \%$ & $\mathrm{~N}=57$ & $\mathrm{P}<0.0001$ \\
Widow(er)s & $45.34 \%$ & $\mathrm{~N}=86$ & $\mathrm{P}<0.0001$ \\
Bachelors & $15.29 \%$ & $\mathrm{~N}=85$ & $\mathrm{P}<0.0001$ \\
\hline
\end{tabular}




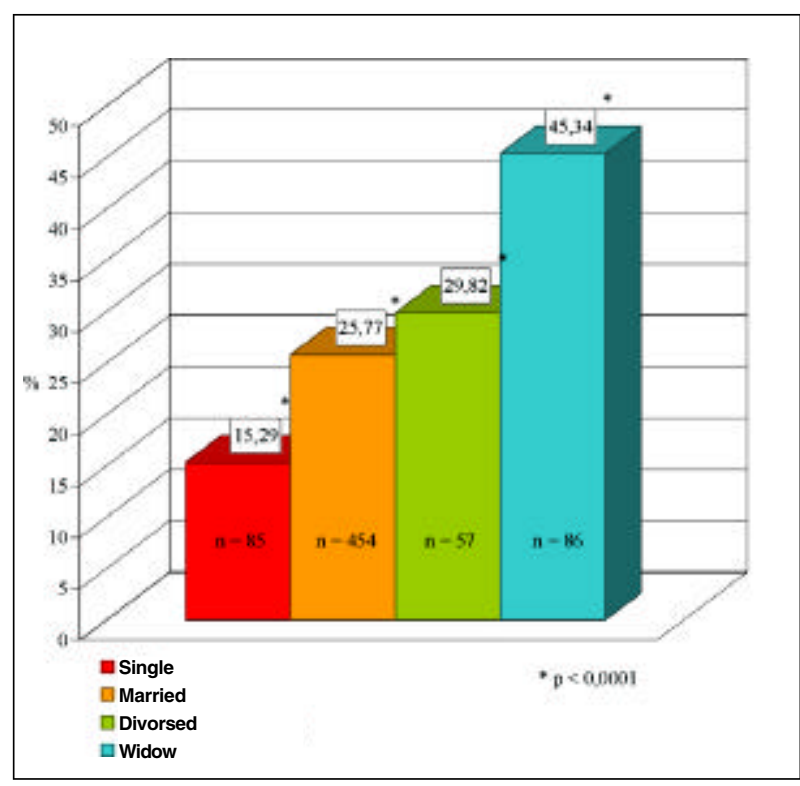

Fig. 3 - Prevalence of systemic hypertension in the groups of different marital statuses in the municipality of Catanduva $(\mathrm{p}<0.0001)$.

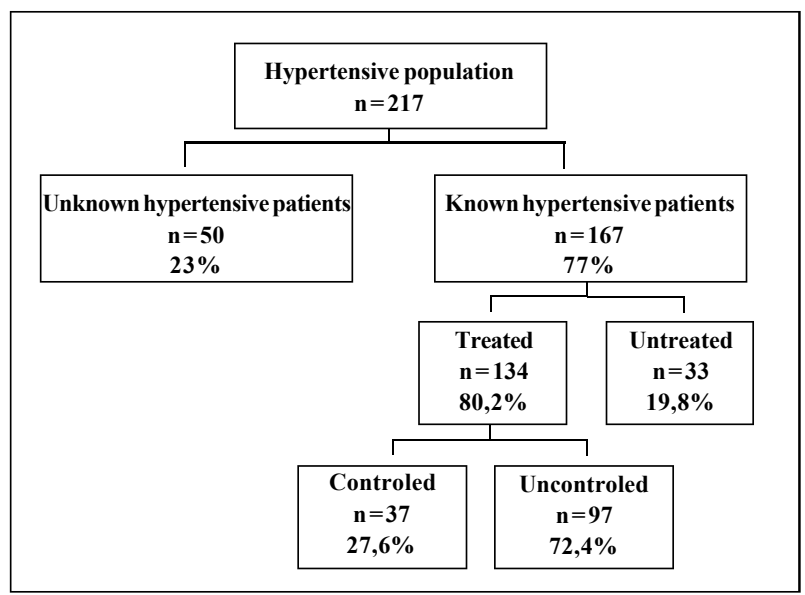

Chart I - Profile of the antihypertensive treatment in the municipality of Catanduva.

The results of the study confirmed the strong correlation between diabetes mellitus and the prevalence of systemic hypertension $(\mathrm{p}=0.05)$. We investigated the 2 forms of diabetes (I and II), whether the interviewees knew in advance they had diabetes, and whether they were treating their disease. Among those reporting not having diabetes, the prevalence of systemic hypertension was $27.8 \%$ $(\mathrm{n}=399)$. Among those with type I or II diabetes, the prevalence was $66.9 \%(\mathrm{n}=46)(\mathrm{p}=0.05)$. Among those who did not know they had the disease and were hypertensive, the prevalence was $19.5 \%(n=231)$. Twelve interviewees did not answer this question (fig. 5).

A result of little significance was that $26.1 \%$ of those individuals not visiting the doctor regularly were hypertensive, and $28.6 \%$ of those visiting the doctor regularly had the disease.

The interviewees ingesting more than $30 \mathrm{~mL}$ of ethanol per day had a prevalence of systemic hypertension of $34.8 \%$, and those who did not drink or who drank less than

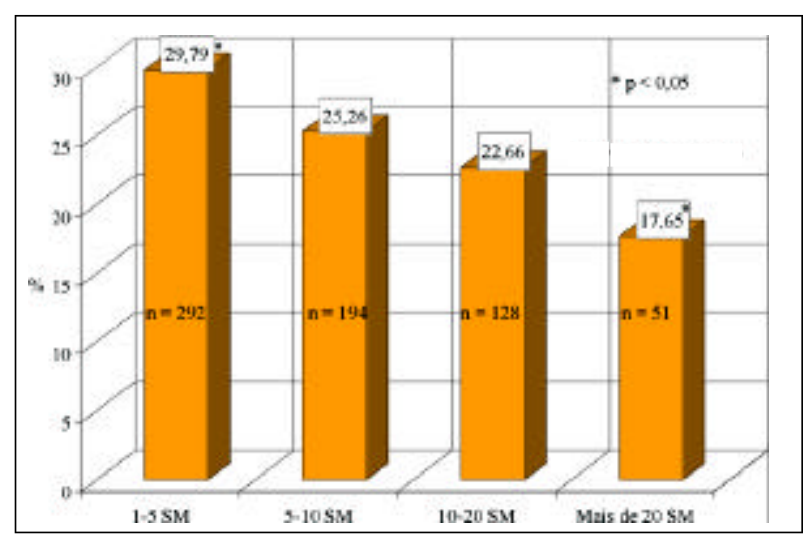

Fig. 4 - Prevalence of systemic hypertension in the groups of different familial incomes in the municipality of Catanduva $(\mathrm{p}<0.05)$, SM: Minimum wage.

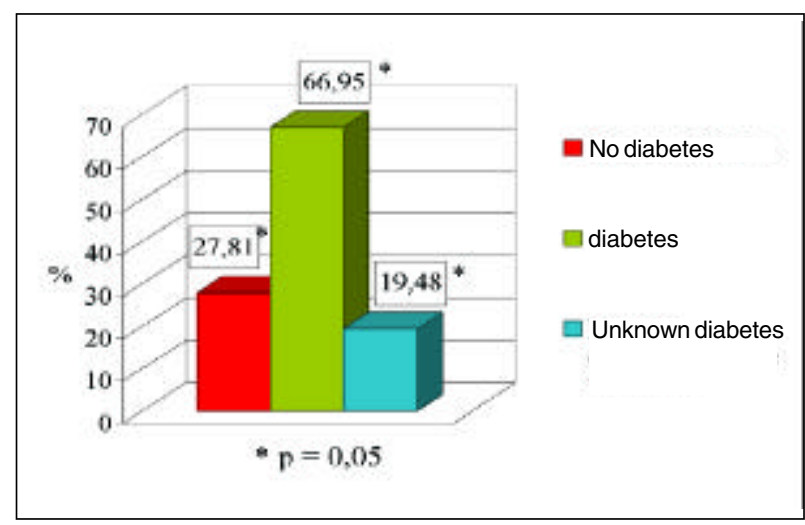

Fig. 5 - Prevalence of systemic hypertension in diabetic and nondiabetic individuals in the municipality of Catanduva $(\mathrm{p}<0.05)$.

$30 \mathrm{~mL}$ of ethanol per day had a prevalence of systemic hypertension of $25.8 \%$ ( $\mathrm{p}=0.05$ ) (fig. 6).

In regard to programmed physical activity (3 times a week, for at least 45 minutes), $23.2 \%$ of the individuals with this practice were hypertensive ( $\mathrm{n}=99$ ). Among those who did not have a programmed physical activity practice, $26.9 \%(\mathrm{n}=491)$ had systemic hypertension. The investigation regarding the history of hypertension among first-degree relatives confirmed previously reported data ${ }^{8-15}$. Prevalence of systemic hypertension in these individuals was $37.8 \%(\mathrm{n}=367)$, and among those who had no hypertensive first-degree relatives it was $12.7 \%(\mathrm{n}=307)(\mathrm{p}<0.0001)$. Fourteen interviewees did not answer this question (fig. 7).

Considering the interviewees, 167 (77\%) knew about their previous hypertensive condition. The remaining 23\% $(n=50)$ had hypertension but did not know about it.

The analysis of body mass index of the population of the municipality of Catanduva showed a strong correlation between obesity and systemic hypertension $(\mathrm{p}<0.001)$ ( fig. 8).

\section{Discussion}

The study carried out in the municipality of Catanduva, in some ways, reports a reality of Brazilian cities. The $31.5 \%$ prevalence of hypertension in a population of 


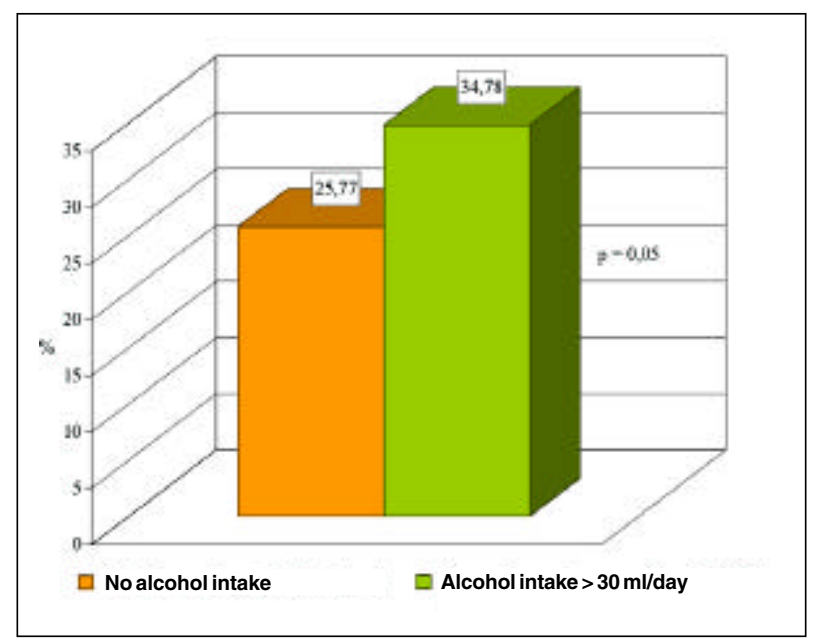

Fig. 6 - Prevalence of systemic hypertension in the interviewees drinking more than $30 \mathrm{~mL} /$ day of ethanol in the municipality of Catanduva $(\mathrm{p}<0.005)$.

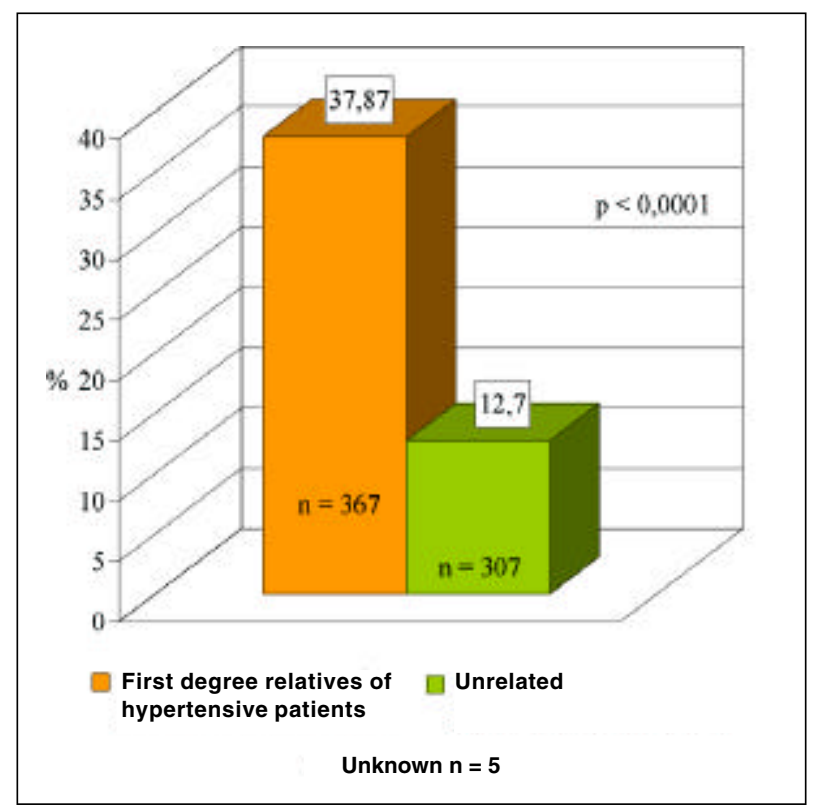

Fig. 7 - Prevalence of systemic hypertension in individuals with familial history of hypertension in the municipality of Catanduva $(\mathrm{p}<0.0001)$.

103,889 inhabitants is not startling, because studies carried out in other Brazilian municipalities have shown prevalence rates higher than $30 \%{ }^{10}$. Even though the criteria used in this latter study were those of the World Health Organization and the criteria adopted in our study were those of the III Brazilian Consensus on Hypertension, both results are considered high for a certain chronic disease.

The inadequate therapeutical control of hypertension deserves special emphasis, because it involves not only the health professional but also primarily the acceptance by the patient of the need to change lifestyles and to adjust the medication for the therapy to become effective ${ }^{21,23}$.

In our study, with antihypertensive control in $27.6 \%$ (chart I) of participants, the change in lifestyle was considered a criterion adequate for treatment that should be prioritized, either associated or not with medicamentous therapy.

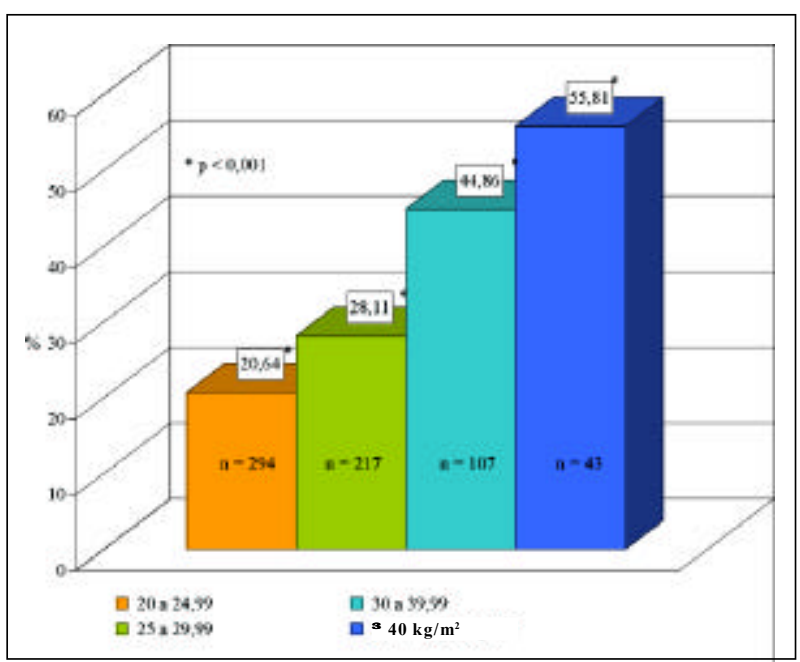

Fig. 8 - Correlation between prevalence of systemic hypertension and body mass index of the interviewees in the municipality of Catanduva $(\mathrm{p}<0.001)$.

Control of blood pressure levels, even though not very common, may be obtained only with changes in lifestyle, as we observed in our study. We also observed that despite medicamentous therapy and appropriate changes in lifestyle, some interviewees did not obtain satisfactory blood pressure levels ${ }^{16}$ (chart I). This low antihypertensive control was mainly due to the difficulty of the hypertensive individual to adequately make changes in lifestyle with appropriate medicamentous therapy, and also to the lack of appropriate medical orientation for the patient to fit a correct treatment program. This inadequacy was also due to the fact that some groups of hypertensive individuals had economic difficulties in obtaining medication that could effectively control hypertension.

In our study, $55.81 \%$ of the individuals with morbid obesity (body mass index $\geq 40 \mathrm{~kg} / \mathrm{m}^{2}$ ) were hypertensive, $44.86 \%$ had body mass index between 30 and $39.99 \mathrm{~kg} / \mathrm{m}^{2}$, and only $20.64 \%$ of the individuals with body mass index between 20 and $24.99 \mathrm{~kg} / \mathrm{m}^{2}$ had systemic hypertension. Therefore, obesity is certainly one of the major factors accounting for systemic hypertension. Correlating all risk factors for systemic hypertension, we observed that the worst association was obesity and familial history of hypertension, which had a prevalence of $28.2 \%$, as compared with $11.2 \%$ of the association with other factors.

In regard to salt ingestion, our study did not find a significant difference between those who admitted taking the salt container to the table during the meals and those who did not, $26.49 \%$ and $25.44 \%$, respectively. This may have resulted from the technical incapacity of measuring the daily intake of $\mathrm{NaCl}$, because of the subjective response and idea that each individual had of the amount of salt present in food, and the difficulty in quantifying the amount of salt in the food ingested, resulting in a higher amount of salt consumed.

In our study, the interviewees with an ethanol ingestion higher than $30 \mathrm{~mL} /$ day had a prevalence of systemic hypertension similar to that found in the literature.

We observed that hypertension prevailed among those who did not have regular physical activity. 
We also observed that the prevalence of systemic hypertension was higher among smokers.

Our study reconfirms that diabetes is one of the major diseases associated with systemic hypertension. The most likely causal link is obesity. Patients with diabetes had a prevalence of systemic hypertension of $66.9 \%(\mathrm{p}=0.05)$, showing that the fact of having type I or II diabetes is closely related to systemic hypertension.

The prevalence of systemic hypertension in males was higher than that in females up to the age of 70 years. This may result from the fact that, in our society, males are less concerned with preventive measures of chronic diseases, such as being physically active, eating healthy food, and not smoking.

A correlation exists between the high workload and the prevalence of systemic hypertension. We could assume that the individual who works more has less or no time for applying measures for changing lifestyles. However, we were not able to obtain a statistical significance between the hours worked $(6,8,10$, and $12 \mathrm{~h})$ and hypertension.

The population of the municipality of Catanduva has a high predominance of white individuals as compared with most Brazilian cities, due to the high concentration of descendants of Italian immigrants. As already reported in previous studies ${ }^{11}$, the proportion of systemic hypertension in white and black people was not the one expected, which may have resulted from the higher proportion of white residents in the municipality of Catanduva (error $\beta$ ).

The fact that the prevalence of systemic hypertension is higher in the group with a lower educational level and lower in the group with a higher educational level may result from parallel factors most of the time, because the individual with a lower educational level has a lower knowledge of how to prevent chronic diseases.

A fact that has not yet been reported in the medical literature and that was observed in our study was the higher prevalence of systemic hypertension in unmarried individuals (divorced/separated and widow(er)s) as compared with that of the married ones. This may have a very plausible explanation because these individuals who are considered unmarried are usually older and, therefore, have a higher tendency toward systemic hypertension.

Heredity was an extremely important factor for systemic hypertension. In our study, we found an elevated level of significance for it, which shows the importance of inquiring about the familial history of hypertension, which should be valued by health professionals.

In conclusion, the prevalence of systemic hypertension found in a municipality of the Northwestern region of the state of São Paulo does not essentially differ from that of other areas. The antihypertensive control is, however, low $(27.6 \%)$. Therefore, we suggest that programs for controlling systemic hypertension should be prioritized and better instruct the population about the reasons that could make compliance with the antihypertensive treatment difficult, jeopardizing the appropriate control of blood pressure and increasing cardiovascular morbidity and mortality.

\section{References}

1. Ennis IL, Gende AO, Cingolani HE. Prevalencia de hipertension arterial en 3154 jovenes estudiantes. Medicina 1998; 58 (5PT 1): 483-91.

2. De Backer G, Myny K, De Henauw S, et al. Prevalence, awareness, treatment and control of arterial hypertension in na elderly population in Belgium. J Hum Hypertens 1998; 12: 701-6.

3. De Henauw S, De Bacquer D, Finteyne W, Stam M, Kornitzer M, De Backer G. Trends in the prevalence, detection, treatment and control of arterial hypertension in the Belgian adult population. J Hypertens 1988; 16: 277-84.

4. Torno MJ, Navarro C, Chirlaque MD, Perez FD. Prevalence and control o arterial hypertension in the south - east of spain: a radical but still in suicient improvement. Eur J Epidemiol 1997; 13: 301-8.

5. Reyes M, Karin M, De los Rios JM. Prevalencia de hipertensión arterial en crampoma Huarochiri - Lima - Perú. Acta Andin 1998; 7: 147-53.

6. Arroyo C, Victor M. Prevalencia de hipertensión arterial en población general Chucuito (Puno). Arequipa 1997; 23 sept: 51.

7. Boffi BHJ, Ustaran JK, Andrade J. Prevalencia de la hipertensión arterial en varones de 18 años de la ciudad Buenos Aires. Medicina 1988; 48: 365-70.

8. Carvalho JJM, Silva NAS, Oliveira JM, Arguelles E, Silva JAF. Pressão Arterial e Grupos Sociais. Estudo Epidemiológico. Arq Bras Cardiol 1983; 40: 115-20.

9. Barreto ML, Meira RLC. Hipertensão arterial em uma comunidade do oeste do Estado da Bahia, Brasil. Arq Bras Cardiol 1980; 34: 363-6.

10. Lolio CA. Prevalência da hipertensão arterial em Araraquara. Arq Bras Cardiol 1990; 55: 167-73.

11. Fuchs FD, Moreira LB, Moraes RS, Bredemeier M, Cardozo SC. Prevalência de hipertensão arterial sistêmica e fatores associados na região urbana de Porto Alegre. Estudo de base populacional. Arq Bras Cardiol 1995; 63: 473-9.

12. Klein CH,Leal MC, Araújo JWG, Silva PCT. Hipertensão arterial em Volta Redonda. Anais do Hospital Siderúrgico de Volta Redonda 1980; 4: 59-63.

13. Barros MA, Arruda Jr.ER, Silva SM, Mendonça MZG. Hipertensão arterial noEstadoda Paraíba. Estudo epidemiológico em 12 municípios interioranos. CCS 1983; 5: 15-18.

14. Trindade IS, Heineck G, Machado JR, et al. Prevalência da hipertensão arterial sistêmica na população urbana de Passo Fundo. Arq Bras Cardiol 1998; 71: 127-30.
15. Ayres JEM. Prevalência da hipertensão arterial na cidade de Piracicaba. Arq Bras Cardiol 1991; 57: 33-6.

16. Carneiro O, Jardim PCBV. Pressão arterial em tribo Xavante. Comparação 15 anos depois. Arq Bras Cardiol 1993; 61: 275-82.

17. Hossne WS. A dignidade como meta. Caderno de Ética em Pesquisa. Comissão Nacional de Ética Médica 1998; ano I: n 1.

18. III Consenso Brasileiro de Hipertensão, fevereiro de 1998

19. Kaplan NM. Measurement of Blood Pressure. In: Kaplan NM, eds. Clinic Hypertension, $6^{\circ}$ ed. Dallas: Williams \& Wilkins, 1994: 23-45.

20. Fletcher RH, Fletcher SW, Wagner EH. Epidemiologia Clínica. Elementos Essenciais. $3^{a}$ ed. Porto Alegre: Artes Médicas, 1996: 200-01.

21 Braunwald E. Tratado de Medicina Cardiovascular. $5^{\text {a }}$ ed. São Paulo: Roca, 1999: 859-915.

22. Sexto Relatório da Comissão Nacional Conjunta de Prevenção, Detecção, Avaliação e Tratamento da Hipertensão Arterial. Archive International Medicine 1997; 157: 2413-41.

23. PerloffD, Grim C, Flack J, et al. Human blood presure. Determination by sphygmomanometry. American Heart Association Medical/Scientific Statement Circulation 1993; 88(part 1): 2459-67.

24. Instituto Brasileiro de Geografia e Estatística (IBGE) ???Ano, ???vol.

25. Klatsky AL, Friedman GD, Armstrong MA. The relationship between alcoholic beverage use and other traits to blood pressure: A new Kaiser permanent study. Circulation 1986; 73: 628-36.

26. Carvalho JJ. Aspecto Epidemiológico e preventivos da hipertensão arterial. Rev Bras Clín Terap 1984; 6: 225-9.

27. Pierin AMG, Mion DJr. Adesão ao tratamento anti-hipertensivo. Hipertensão 1999; 2: 9-15.

28. Bloch KV, Klein CH, Silva NAS, Nogueira AR, Campos LHS. Hipertensão arterial e obesidade na Ilha do Governador - Rio de Janeiro, RJ. Arq Bras Cardiol 1994; 62: 17-22

29. Ribeiro AB. Hipertensão arterial como síndrome São Paulo. Ass Med Brasil 1997; 43: 179.

30. Figthing disease e stroke edited by American Heart Association, 1997; 2: 131-42. 